\title{
The Effect of the Roadway with the GFRP Bolting by Numerical Analysis and Application
}

\author{
Changfu ZOU ${ }^{1}$ \\ Chongqing Research Institute of China Coal Technology \& Engineering Group \\ Corporation, Chongqing, China
}

\begin{abstract}
Based on the FLAC3D numerical software, a roadway excavation and support model was established. The stability of the surrounding rock of the FRP bolt support and the force characteristics of the bolt support in the Yuhuasi mining area of Jinshandian Iron Mine were analyzed. The distribution law of the plastic zone of the roadway and the distribution characteristics of the bolt support force were simulated, and the deformation law of the roadway support was simulated. The roadway deformation data for 6 months of support was tested on site, the weak links of the support were determined, and the support was optimized. Parameters, the optimized support effect is better, which provides a guarantee for the safety of roadway support and also provides a reference for other metal mine roadway support.
\end{abstract}

Keywords. FLAC3D, roadway supporting, GFRP bolt, numerical simulation, stability analysis.

\section{Introduction}

During the mining process of the stopping roadway, affected by factors such as ground pressure and geological conditions, the two sides of the roadway and the roof are extremely prone to displacement, deformation and collapse. Effective measures must be taken for support. At present, bolt support is mainly used in China. Fast support, and the main types of bolts are threaded steel bolts and resin bolts. The threaded steel bolts are prone to corrosion and failure in the moist underground environment. The resin bolts have the advantages of corrosion resistance, high strength, and cutting ability. It is widely used, among which the strength of FRP bolts is relatively high, and the materials can meet the requirements of ultimate strength such as tensile, shear, and yield, and are used in a large area in the process of underground mine tunnel support [1-3]. However, in the actual support process, due to the lack of clarity of the bolt stress state and the location of the force point, the location of deformation and collapse cannot be predicted in advance, which leads to the phenomenon of missing support at the deformation and collapse point during the support process. Protection failure also often occurs [4-6]. In order to avoid missing support or repeated support, it is necessary to simulate and analyze the mechanical properties of the surrounding rock of the roadway and the mechanical state after support in advance, and predict possible support failure accidents in advance to reduce support safety accidents.

1 Corresponding Author, Changfu ZOU, Chongqing Research Institute of China Coal Technology \& Engineering Group Corporation, Chongqing, China; Email: 3051617571@qq.com. 


\section{Roadway Support Simulation}

\subsection{Roadway Overview}

Aiming at the problem of transportation roadway support in the stope of Yuhuasi mining area in Jinshandian Iron Mine of Baowu Steel Group, FLAC ${ }^{3 \mathrm{D}}$ software was used for numerical simulation analysis. The roadway is a three-center arch section of $3.8 \mathrm{~m} \times 3.3 \mathrm{~m}$. It is supported immediately after the roadway is formed. During the supporting process, $\Phi 18 \times 1800 \mathrm{~mm}$ left-handed glass fiber reinforced plastic bolts are used for support. Density $\gamma=1.9 \mathrm{t} / \mathrm{m}^{3}$. The diameter of the supporting hole is $40 \mathrm{~mm}$, and each supporting hole is anchored with a fast-hardening cement coil for the full length, and the anchoring length is $1800 \mathrm{~mm}$. The two sides and roof of the roadway are supported by sprayed concrete, the concrete strength is $20 \mathrm{Mpa}$, and the sprayed layer thickness is $80-100 \mathrm{~mm}$. The roof of the roadway is relatively broken, and the anchor net is used for reinforcement. The anchor net is a $200 \times 200 \mathrm{~mm}$ diamond-shaped metal net made of $8 \mathrm{~mm}$ iron wire, with a length of $3300 \mathrm{~mm}$ and a width of $1000 \mathrm{~mm}$, covering the entire top of the roadway.

\subsection{Roadway Support Simulation}

For roadway support simulation analysis, the $\mathrm{FLAC}^{3 \mathrm{D}}$ software commonly used in surrounding rock stability analysis is used to simulate the progressive failure and deformation of the support. Based on the modeling and analysis of the support technology characteristics of the mining roadway in Jinshandian Iron Mine [7-10]. The geological characteristics of the mining roadway in the Yuhuasi mining area of Jinshandian show that it is the surrounding rock ore body layer dominated by magnetite. Therefore, in the simulation process, a one-to-one modeling is carried out based on the size of the roadway section and the length of the support, but considering the outside world The environment is more complicated, and some external factors with low influencing factors are simplified, that is, the roadway model is simplified to a continuous and uniform magnetite rock mass. In the process of roadway stress, the initial force is its own weight, and the roadway is only considered when the force is applied later. The stress change caused by excavation does not consider the seepage caused by groundwater at the same time. According to the nature of the magnetite rock mass, the geological data is queried to determine its mechanical parameter values and input into the boundary conditions. According to the section size and anchoring support length, and considering the influence of the boundary effect, the model takes $36 \mathrm{~m}$ in the direction of the roadway section. Height $36 \mathrm{~m}$; because the roadway support can be simplified as a plane problem, in order to reduce the calculation grid, take the axial direction of the roadway as the length direction, only take $10 \mathrm{~m}$ for numerical analysis, and determine the size of the entire model as length $\times$ width $\times$ height $10 \mathrm{~m} \times 36 \mathrm{~m} \times 36 \mathrm{~m}$, after the mesh is divided, there are a total of 34776 structural units. The model established is shown in figure 1. 


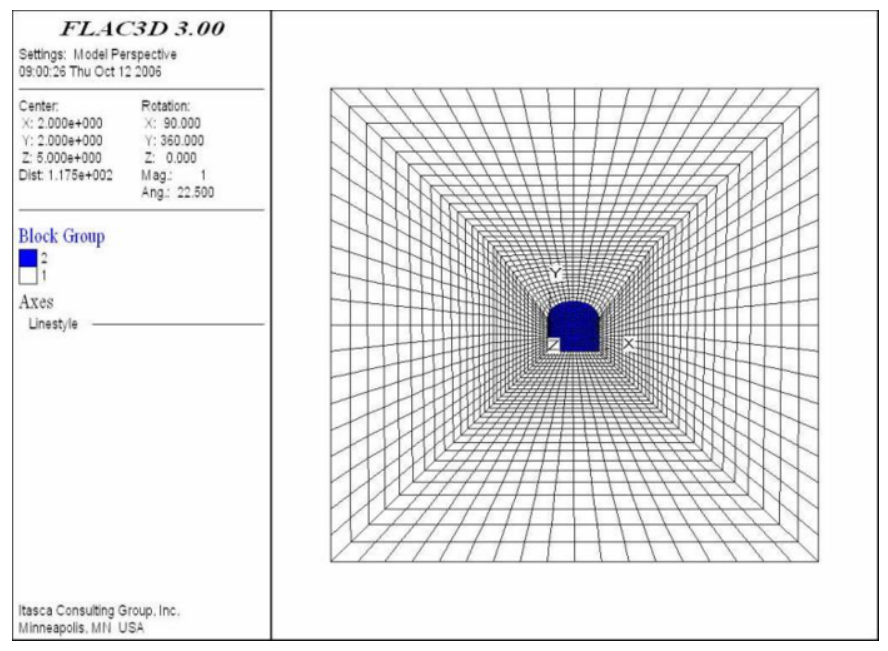

Figure 1. Roadway model diagram

The FRP bolt support adopted for roadway support, the material properties and mechanical characteristic values of FRP bolts are configured into the grid as required. The empty area before and after the excavation of the roadway is not affected by the stress, and the built-in zero model is used for calculation, and the surrounding rock part of the roadway is affected by the ground pressure before and after the excavation, so the Mohr-Coulomb plasticity of the force analysis is selected. The model is calculated. Therefore, in the roadway excavation model, the two sides of the roadway and the roof are both stressed areas. In the model, the positions of the arch angles and side sides on the left and right sides of the model are symmetrical to the center line, and the top and two sides of the roadway are supported in accordance with the actual support. The row spacing is equipped with bolt support units. At the nut and pallet support points, the members near the roadway wall are assigned maximum values to simulate the role of the pallet. The finally established bolt support unit model diagram is shown in figure 2 .

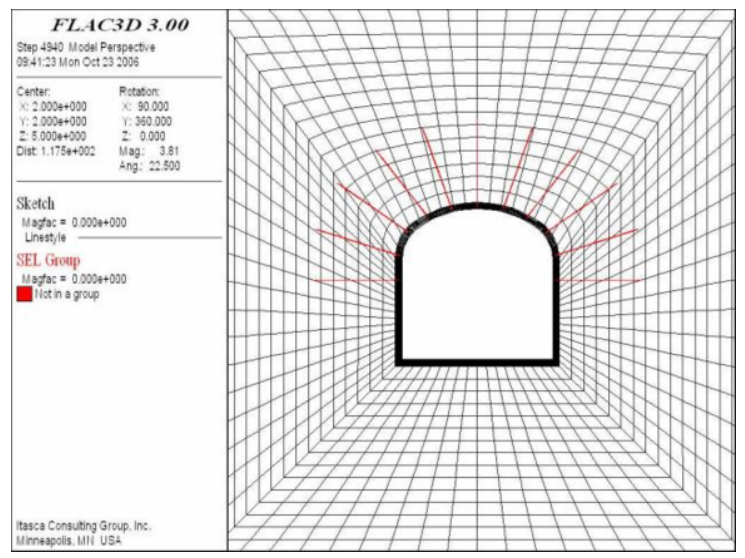

Figure 2. Anchor support model diagram

In order to analyze the stress situation of the roadway roof and the two sides later, the typical stress points on the roadway roof and two sides are selected for 
displacement monitoring, as the displacement monitoring points, and the roadway roof and the two sides are measured before the excavation and after the support. The displacement and deformation in the radial and radial directions, and the setting of monitoring points are shown in figure 3.

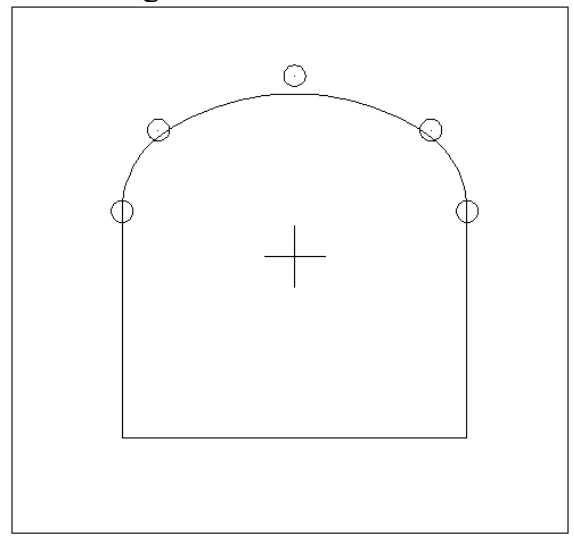

Figure 3. Location map of monitoring points

\section{Support Simulation Analysis}

According to the support parameters of the mining roadway and the actual situation of the site, the numerical software simulation analysis shows that when the mining roadway of Jinshandian Iron Mine is supported by FRP bolts, the original rock stress zone and elastic zone formed after the support of the roadway are relatively stable. The plastic zone is extremely easy to deform with the development of support time. Therefore, the shape of the plastic zone can indirectly reflect the deformation trend after support. According to the simulation, the plastic area of the roof, floor and the center zone of the two sides of the roadway is small after the support, while the angle between the roof and the two sides of the roadway, and the angle between the bottom and the two sides all show larger plastic areas, and Extending to the deep area, the plastic area of the roadway support section shows a "butterfly" distribution. The simulation shows that the plastic zone distribution of the mining roadway is shown in figure 4 . 


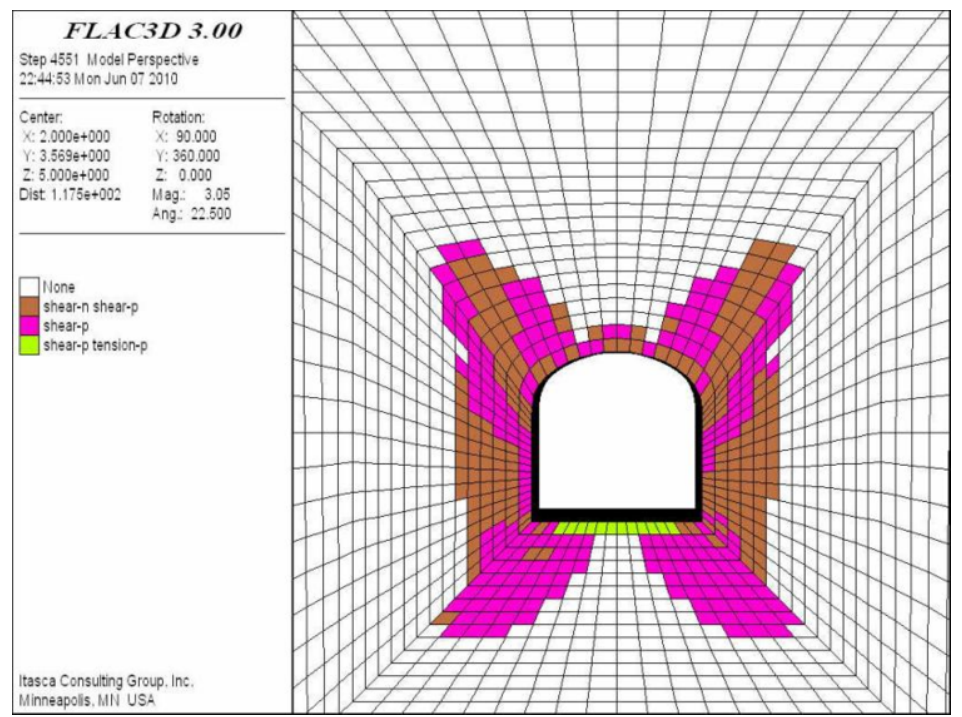

Figure 4. Plastic zone of roadway section

After the support has formed the plastic zone, with the accumulation of the support time, the roadway displacement and deformation will gradually increase. The FRP bolt support plays a supporting and stabilizing role through the axial force of the bolt. The stress form changes from one-way compression and two-way compression to three-way compression, thereby improving its hoop compressive strength, so that the compression belt can bear its own weight and a certain external load, making it effective Control the deformation of surrounding rock. Therefore, after adopting FRP bolt support, its stress state and its mechanical characteristics are important factors for judging whether the bolt support can effectively resist the deformation of the roadway. Through software simulation, the distribution of axial force after adopting FRP bolt support after roadway excavation is shown in figure 5. Among them, in the two sides of the roadway and the roof area, the bolts supported by the two sides of the roadway bear The axial force is relatively large and gradually decreases toward the center of the roof of the roadway. At the center of the roof of the roadway, the axial force that the bolt bears is the smallest and the distribution is relatively uniform; in the single bolt support area Inside, the support end close to the excavation of the roadway bears the largest axial force, and the maximum value appears at the stress point of the nut and tray of the support end, and shows a gradually decreasing trend toward the depth of the surrounding rock; From the overall distribution point of view, the axial force borne by the bolt support presents a symmetrical distribution with the centerline of the roadway as the axis; from the point of view of the force characteristics, the axial force borne by the bolt support process is mainly Appears as tensile stress. Through simulation analysis, it can be seen that the maximum tensile stress during the support process of Jinshandian Iron Mine reached 227.3 MPa, which did not exceed the pressure range of FRP bolts. At the same time, the point with greater pressure is close to the end of the orifice, which reduces the internal surrounding rock. Bearing pressure is conducive to bolt support to resist the deformation of the surrounding rock wall. 


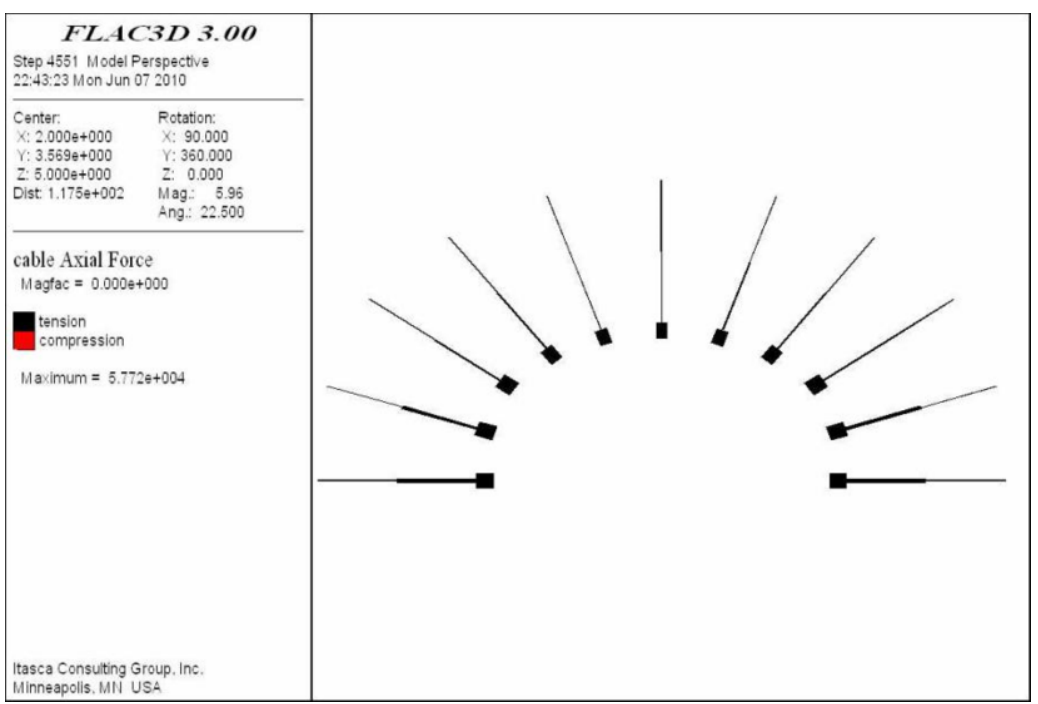

Figure 5. Distribution characteristics of axial force of FRP bolt support

\section{Supporting Effect Analysis}

According to the results of numerical simulation analysis, it can be seen that the corner between the top plate and the two sides is most prone to deformation and collapse, and the corner between the bottom plate and the two sides is most prone to deformation of the bottom drum. The axial force is low in the roof position, which is manifested as the roof is prone to deformation and collapse. The comprehensive plastic zone and support force can be seen. The key areas in the support process are the roadway roof, the angle between the roadway roof and the two sides. To avoid collapse, and at the same time, we should deal with the accumulation of water on the bottom plate to avoid deformation of the bottom drum [11-12]. According to the support parameters of the mining roadway in Jinshandian Iron Mine, the simulation analysis shows that the current vertical displacement and the horizontal displacement of the two sides of the glass fiber reinforced plastic bolt support are shown in figure 6. From top to bottom, there are the horizontal displacement of the left side, the horizontal displacement of the left top side, the horizontal displacement of the right top side, the horizontal displacement of the right side, the vertical displacement of the left top side, the vertical displacement of the arch angle and the vertical displacement curve of the dome. According to the curve characteristics, it can be seen that the displacement of the two sides of the roadway, the top side, the arch angle and the dome are different. The displacement of the dome and the arch corner is larger than the deformation of the two sides, and the vault shows a vertical displacement. The sides are represented as horizontal displacements, where the area with the largest vertical displacement appears at the vault position, with a deformation of about $2.81 \mathrm{~mm}$; the second is the arch angle and the top with a deformation of $2.54 \mathrm{~mm}$ and $1.59 \mathrm{~mm}$, respectively; the area with the largest horizontal displacement appears at the top of the vault. The deformation of the two gangs is $1.34 \mathrm{~mm}$, followed by the junction of the two top gangs with a deformation of $0.87 \mathrm{~mm}$. It can be seen that the main forms of deformation of the mining roadway in 
Jinshandian Iron Mine are vertical deformation and horizontal deformation. At the same time, the deformation of the roof subsidence is greater than the shrinkage deformation of the two sides.

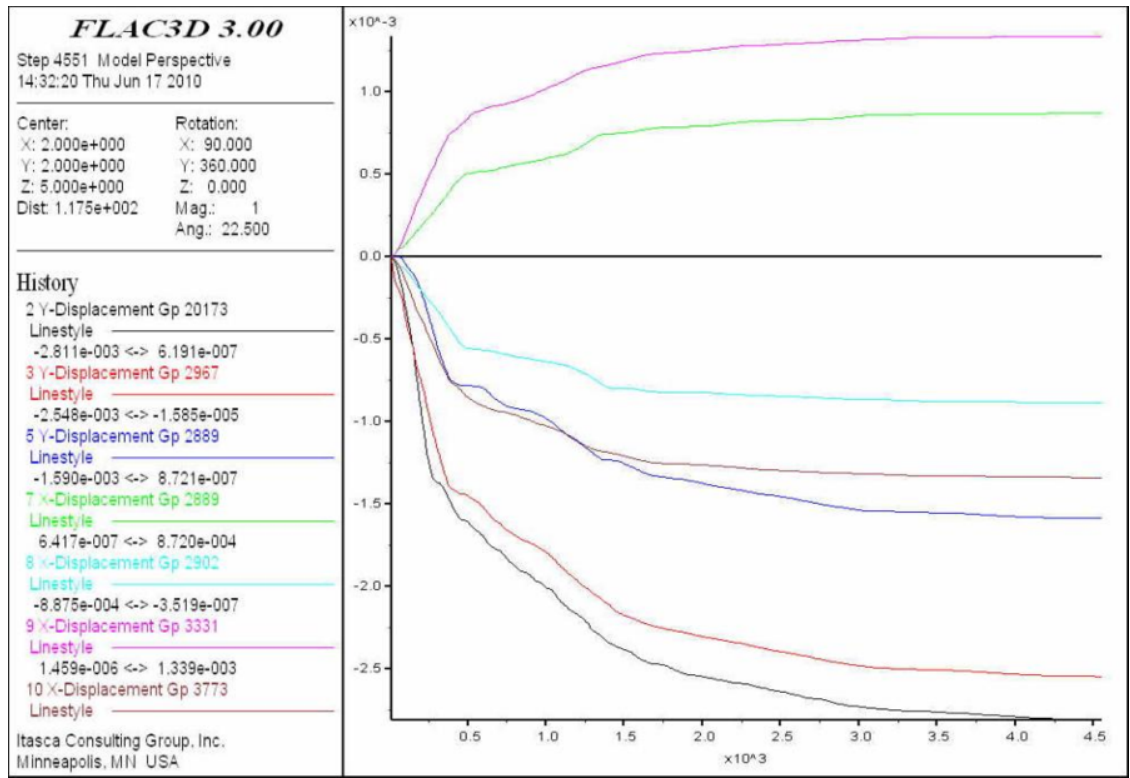

Figure 6. Deformation after FRP bolt support

According to the on-site support situation of the Jinshandian Iron Mine, the displacement monitoring was carried out for 6 months after the support. The displacement curves of the roof and the two sides are shown in figure 7 . The roof and the two sides of the support began to show large deformations after one month. The deformation of the roof of the roadway accumulates with time, and the deformation rate is gradually increasing. The maximum deformation reaches $450 \mathrm{~mm}$, especially for the support for about 5 months, the deformation of the roof increases sharply, Field observation, the roof collapse phenomenon; the deformation of the two sides of the roadway accumulated over time, the deformation rate gradually slowed down, and the deformation reached more than $100 \mathrm{~mm}$, with the passage of time, the deformation amplitude was small, the deformation reached the limit, field observation, Cracks and partial collapse appeared in the two sides. 


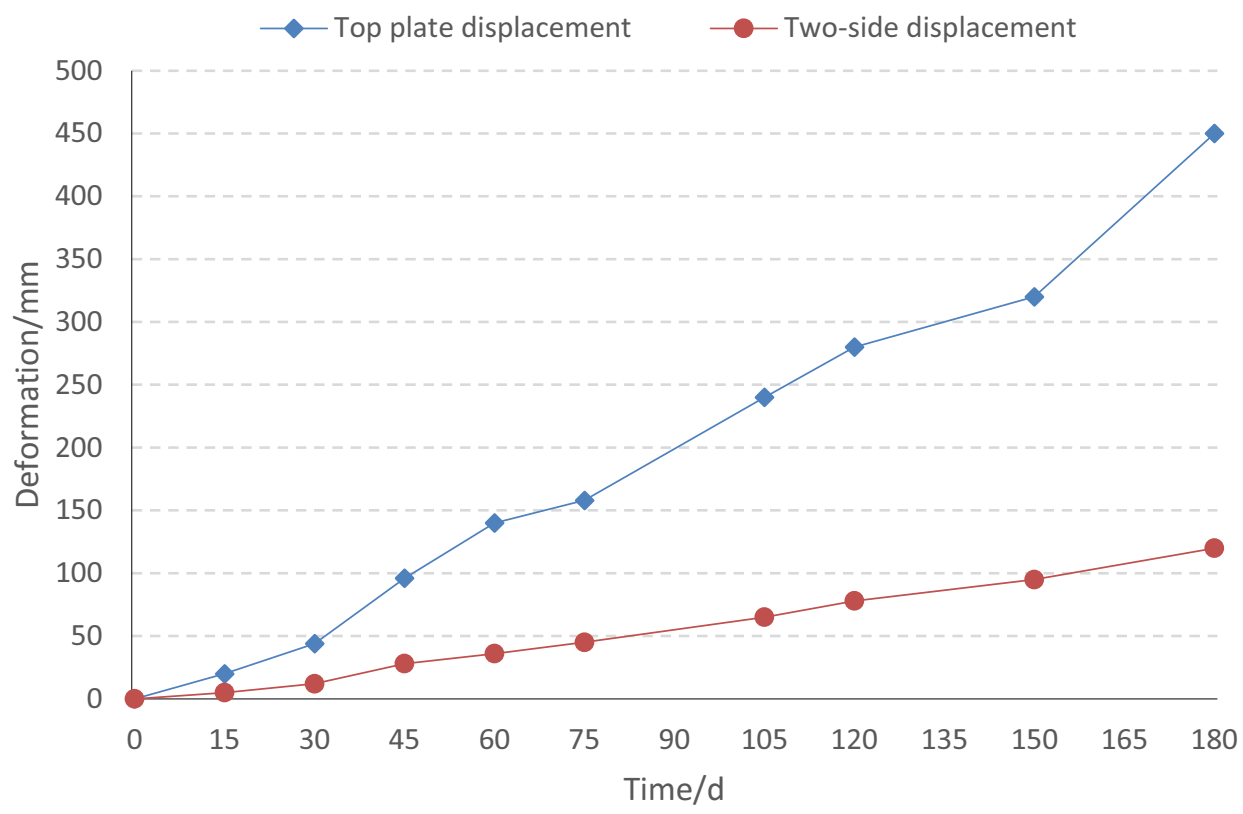

Figure 7. Supporting deformation curve

According to the on-site support monitoring situation, dense support was carried out at the collapsed position of the roadway roof, and at the same time reinforced support was carried out at the angle between the roof and the two sides, and the two sides of the roadway were sprayed with concrete for anchoring, and displacement monitoring and support were continued. According to the effect observation, after 6 months of monitoring, the deformation of the roof did not exceed $200 \mathrm{~mm}$, and the deformation of the two sides did not exceed $100 \mathrm{~mm}$. The overall stability of the roadway after support was good. After the optimization of the support, the field observation found that the roof Only cracks appear in the broken zone, and the two sides have no obvious deformation. The on-site support effect is better, which effectively guarantees the safety of the support.

\section{In Conclusion}

Through the numerical simulation and analysis of the support of FRP bolts in the roadway of Jinshandian Iron Mine, the following conclusions can be obtained:

(1) After the roadway is supported, the plastic area of the roof, the bottom plate and the center zone of the two sides is small, while the angle between the roof and the two sides of the roadway, and the angle between the bottom plate and the two sides is larger, and extends to the deep area. The plastic zone of the protective section is distributed in a "butterfly shape".

(2) The axial force suffered during the bolt support process is mainly manifested as tensile stress, which presents a symmetrical distribution shape with the centerline of the roadway as the axis, and the maximum value appears at the stress point of the nut and 
the tray at the end of the support. And gradually lower to the depths of the surrounding rock.

(3) The deformation of the roadway is mainly vertical deformation and horizontal deformation. The amount of roof subsidence deformation is greater than the shrinkage deformation of the two sides, and the cumulative roof deformation rate gradually increases with time, while the deformation rate of the two sides tends to be gentle.

(4) For the roadway with high stress, strengthen the support at the roof and the angle between the roof and the two sides, and perform shotcrete anchoring on the two sides. The optimized support effect is better, which provides a guarantee for the safety of the roadway support. It also provides a reference for other metal mine roadway support.

\section{References}

[1] Jun Huang, Yicheng Ye, Wenjie Wang, et al 2010 Experimental Research on Tensile and Shear Properties of GFRP Bolt Based on Application[J]. China Mining 19(10) 94-96+112.

[2] N.Barton,R. Lien,J. Lunde 1974 Engineering classification of rock masses for the design of tunnel support[J]. Rock Mechanics Felsmechanik Mécanique des Roches . 1974 (4)

[3] Wenjie Wang, Fengyu Ren 2008 Rock mass stability classification and bolt support parameter optimization in Chambixi Copper Mine[J]. China Mining 4(7), 58-61.

[4] Guide for the design and construction of externally bonded FRP systems for strengthening concrete structures. ACI Committee.2000.

[5] Brahim Benmokrane, Haixue Xu, Eric Bellavance 1996 Bond strength of cement grouted glass fibre reinforced plastic (GFRP) anchor bolts[J]. International Journal of Rock Mechanics and Mining Sciences and Geomechanics Abstracts. 1996 (5).

[6] Wenjie Wang, Xiongzhong Ma, Changfu Zou et al 2012 Current Tests and Existing Problems of FRP Bolt Supporting in Jinshandian Iron Mine [J]. Metal Mine 10: 1-4+8.

[7] Jianmin Zhu, Binye Xu, Feng Zhu et al 2000 FLAC finite difference program and its application in mines volume_up content_copy share [J]. China Mining 4(4): 98-102.

[8] Zejin Wang 2000 Application of Finite Difference Numerical Simulation Method in Design of Bolt Supporting in Coal Roadway with Broken Roof[J]. Coal Mining 4(3): 29-31+4.

[9] Ove Stephansson 2021 Rock bolting: Theory and application in mining and underground construction. Proceedings of the International Symposium (Abisko, Sweden) 28 August-2 September 1983[B] CRC Press, 2021.

[10] Changfu Zou 2012 Research on Application of FRP Bolt Support in Daye Iron Mine[D]. Wuhan University of Science and Technology.

[11] Yue Cai, Tetsuro Esaki, Yujing Jiang 2004 An analytical model to predict axial load in grouted rock bolt for soft rock tunneling Tunnelling and Underground Space Technology.

[12] V. M. Karbhari, J. W. Chin, D. Hunston, B. Benmokrane, T. Juska, R. Morgan, J. J. Lesko, U. Sorathia, D. Reynaud 2003 Durability Gap Analysis for Fiber-Reinforced Polymer Composites in Civil Infrastructure[J]. Journal of Composites for Construction . 2003 (3) 